\title{
A educação eugênica nos Annaes de Eugenía
}

\section{Resumo}

Este artigo tem como propósito problematizar as relações entre eugenia e educação no Brasil, tomando como objeto de análise algumas das proposições científicas encontradas nos Annaes de Eugenía, documento que reúne os registros das atividades realizadas da Sociedade Eugênica de São Paulo, fundada em 1918. Através da análise dos postulados eugenistas formulados por Renato Kehl (18891974) e Fernando de Azevedo (1894-1974), interessa evidenciar como, muito precocemente, os teóricos eugenistas locais elegeram a educação como uma forma privilegiada de promoção do melhoramento racial da população brasileira, buscando com isso compreender a forma como o nascente movimento social em favor da ciência do melhoramento racial definiu os preceitos da chamada educação eugênica.

Palavras-chave: Eugenia. Educação. Educação eugênica.

\section{Gustavo da Silva Kern}

Instituto Federal de Santa Catarina -

IFSC - Florianópolis/SC - Brasil xkern@hotmail.com

\section{Para citar este artigo:}

KERN, Gustavo da Silva. A educação eugênica nos Annaes de Eugenía. Revista Linhas. Florianópolis, v. 21, n. 45, p. 301-321, jan./abr. 2020.

\section{DOI: 10.5965/1984723821452020301}

http://dx.doi.org/10.5965/1984723821452020301 


\title{
Eugenic education in the Annaes of Eugenics
}

\begin{abstract}
The present paper aims to problematize the relationship between eugenics and education in Brazil, the object of the analysis is to investigate some of the scientific propositions found in the Annals of Eugenics. This document gathers the records of the activities carried out by the Eugenic Society of São Paulo, founded in 1918. Through the analysis of eugenic hypothesizes proposed by Renato Kehl (1889-1974) and Fernando de Azevedo (1894-1974), it is interesting to show how, very early on, local eugenic theorists chose education as a privileged way to promote the racial improvement of Brazilian population. We try to understand how the beginning social movement in favor of the science of racial improvement defined the principles of the so-called eugenic education.
\end{abstract}

Keywords: Eugenics. Education. Eugenic education. 
O presente artigo tem por objetivo problematizar as relações entre eugenia e educação no Brasil, tomando como objeto de análise algumas das proposições científicas encontradas nos Annaes de Eugenía'. O volume, publicado originalmente em 1919 pela prestigiada editora Revista do Brasil, reúne os registros das atividades realizadas durante o período de funcionamento da Sociedade Eugênica de São Paulo, contendo os trabalhos apresentados, as atas de reuniões e o estatuto da entidade científica fundada em 15 de janeiro de 1918. Através da análise dos postulados científicos formulados por Renato Kehl (1889-1974) e Fernando de Azevedo (1894-1974), interessa-me sobremaneira evidenciar como, muito precocemente, os teóricos eugenistas locais elegeram a educação como uma forma privilegiada de promoção do melhoramento racial da população brasileira.

Esse melhoramento racial deveria ter por base os ensinamentos de uma nova doutrina científica, estabelecida em seus pressupostos fundamentais pelo inglês Francis Galton (1822-1911) em trabalhos publicados nas últimas décadas do século XIX. O teórico vitoriano definiu a eugenia como "a ciência que trata de todas as influências que melhoram as qualidades inatas de uma raça, bem como das qualidades que se pode desenvolver até alcançar a máxima superioridade." (GALTON, 1988, p. 165). No Brasil, onde o racismo científico europeu havia encontrado ampla recepção, a ciência do melhoramento racial, e sua promessa de evolução biológico-social através do controle da hereditariedade, foi recebida com grande interesse pela intelligentsia local, imiscuindo-se no debate em torno da modernização educacional do país.

No transcorrer das primeiras décadas do século XX, aconteceu a formação de um movimento social, integrado por uma reduzida elite intelectual, que militou firmemente em favor da materialização dos ensinamentos da ciência do melhoramento racial no Brasil. Os teóricos eugenistas produziram uma discursividade caracterizada, sobretudo, pela pretensão científica e política de empreender uma verdadeira regeneração racial da população nacional - projeto de caráter marcadamente biopolítico, tendo-se em conta a perspectiva desenvolvida por Michel Foucault ${ }^{2}$. Desde a constituição do movimento

\footnotetext{
${ }^{1}$ Utilizarei, por vezes, a forma elipsada Annaes para me referir aos Annaes de Eugenía.

2 As teorias eugenistas produzidas no Brasil, no transcorrer da primeira metade do século XX, foram instituídas e instituíram efeitos relativos ao funcionamento do que Foucault chamou de biopoder. Em $A$ vontade de saber, o biopoder é definido como "um poder que se exerce, positivamente, sobre a vida, que empreende sua gestão, sua majoração, sua multiplicação, o exercício, sobre ela, de controles precisos e regulações de conjunto." (FOUCAULT, 1988, p. 149). O principal objetivo do biopoder é, portanto, "gerir a
} 
eugenista local, que teve como marco a fundação da Sociedade Eugênica de São Paulo, seus agentes procuraram recorrentemente definir a função da educação junto ao processo de melhoramento racial da população nacional, tendo como fundamento a compreensão de que tanto as medidas eugenistas quanto as medidas educacionais formuladas no âmbito do discurso eugenista, teriam por objetivo comum realizar a regeneração racial do corpo coletivo da nação.

O texto que segue está dividido em duas partes. Na primeira delas, procuro discutir a concepção eugenista presente nos Annaes. Já na segunda parte do texto, tomando por objeto de análise alguns dos trabalhos publicados nos Annaes, busco compreender como a educação foi inserida como elemento presente na gênese do discurso eugenista formulado nas primeiras décadas do século XX. Analisando trabalhos seminais de teóricos eugenistas como Kehl e Azevedo, notabilizados nacionalmente por sua prolífica produção intelectual entre as décadas de 1920 e 1940, é possível evidenciar a relevância que a educação prontamente assumiu junto ao processo de emergência do discurso eugenista, mas também caracterizar a forma como o nascente movimento social em favor da ciência do melhoramento racial definiu os preceitos da chamada educação eugênica.

\section{Os Annaes de Eugenía e a constituição do discurso eugenista}

Compreender a importância dos textos reunidos nos Annaes de Eugenía publicado pela editora da Revista do Brasil em 1919 - faz-se tarefa quase obrigatória para o estudioso da história do discurso eugenista produzido no Brasil. A relevância historiográfica do documento reside, antes de mais nada, no fato de que os trabalhos eruditos e científicos reunidos no volume apresentam os fundamentos seminais do programa reformista em torno do qual se articulou o movimento eugenista local no transcorrer das primeiras décadas do século XX. Os Annaes registram nada menos que a emergência histórica do fenômeno político-científico que o médico paulista Renato Kehl, ainda em meados do século XX, elogiosamente denominava por “cruzada eugenista”.

vida." (FOUCAULT, 1988, p. 151) dos homens, potencializando as capacidades do corpo coletivo constituído pela população. Projetando intervenções sobre a constituição racial da população brasileira, o que estava em jogo nesse discurso eugenista local era o efetivo exercício do biopoder. 
Nos Annaes é possível encontrar, por exemplo, a Conferencia de propaganda eugenica que Kehl proferiu na Associação Cristã de Moços (ACM) de São Paulo em 13 de abril de 1917 — sendo publicada dias depois, em 19 de abril, no Jornal do Comércio. Na ocasião, o jovem farmacêutico e médico, que posteriormente se tornaria o principal expoente do movimento eugenista constituído no Brasil, proferiu sua conferência em função de um convite recebido diretamente dos diretores da ACM paulistana. Kehl (1919a, p. 68), que inaugurava sua estratégia política de divulgação militante das ideias eugênicas, definiu a eugenia como a ciência que se dedica "a estudar as condições mais favoráveis para o levantamento da raça humana e a fixar as regras para a boa reprodução", em favor do aprimoramento "dos caracteres physicos e moraes das gerações futuras." (KEHL, 1919a, p. 69). Para atingir tais propósitos, argumentava, a eugenia se fundamentara sobre as concepções da hereditariedade desenvolvidas por Jean-Baptiste Lamarck (1744-1829), Charles Darwin (1809-1882) e Gregor Mendel (18221884). A hereditariedade, constituindo-se como o próprio fundamento da eugenia, é com ênfase definida como "a lei biologica debaixo da qual os sêres vivos tendem a se repetir nos seus descendentes e a lhes transmitir as suas propriedades." (KEHL, 1919a, p. 69).

Dadas as características da formação da população brasileira, baseada em "cruzamentos intensos de mesclada heterogeneidade, de descuidada promiscuidade entre adventícios e forasteiros." (KEHL, 1919a, p. 69), a preocupação com a herança biológica determinada pela lei da hereditariedade seria imprescindível para o futuro nacional. Somente a intervenção eugênica sobre a hereditariedade permitiria "eliminar o sub-homem, melhorando o typo humano, evitando a decadencia” (KEHL, 1919a, p. 68), e, assim, "salvaguardar a descendência da degeneração." (KEHL, 1919a, p. 69). Além da necessária "lucta contra as endemias e epidemias" que assolavam todos os recantos do território nacional, exemplarmente realizada pelos médicos sanitaristas e higienistas, seria imperiosa a "necessidade de ampliarmos esses zelos humanitários, cuidando da nossa raça, para torna-la sã, forte e robusta." (KEHL, 1919a, p. 68). As medidas eugenistas, com sua lógica eminentemente biopolítica, permitiriam potencializar a vida da população brasileira por meio de seu melhoramento biológico-racial, eliminando a degenerescência própria aos considerados “sub-homens”. 
Kehl também procurou chamar atenção para o fato de que o momento histórico - marcado pela tomada de posição do Brasil em favor dos aliados na Primeira Guerra Mundial (1914-1918) e da nova posição que ambicionava conquistar no palco das nações - seria muito oportuno para se conceder uma maior atenção aos ensinamentos da eugenia. Estaríamos conhecendo um “pleno desenvolvimento de idéaes nacionalistas", com o despertar das "forças regeneradoras" que atuariam em favor da "grandeza da nacionalidade" (KEHL, 1919a, p. 67). Como afirma Nancy Stepan (2004, p. 335), é importante observar que a constituição do movimento eugenista local tenha acontecido no contexto de crise desencadeado pelo conflito bélico, pois, enquanto nos países europeus a guerra "intensificara o medo da degeneração nacional, no Brasil ela gerou um novo otimismo sobre a possibilidade de regeneração nacional, um otimismo que contrabalançava os receios mais tradicionais de decadência."

A ampla divulgação da conferência proferida na ACM, por meio de sua publicação integral nas páginas do Jornal do Comércio, diz muito sobre a receptividade que a ciência do melhoramento racial rapidamente encontrou no Brasil. Kehl (1919a, p. 78), atento aos ensinamentos de Galton, desde o princípio de sua "cruzada eugenista" insistiu que a "campanha eugenica deve ser uma das preocupações da imprensa do nosso paiz"3. Afinal, fazer repercutir publicamente as ideias eugênicas seria essencial para que se multiplicassem "os cultores da sciencia do bem geral, dessa grandiosa protectora das raças do futuro." (KEHL, 1919a, p. 79). De fato, a visão retrospectiva permite afirmar que a repercussão pública da conferência de Kehl foi fundamental para o destino da eugenia no Brasil, pois permitiu reunir as atenções necessárias para articular a criação da pioneira Sociedade Eugênica de São Paulo.

Fundada oficialmente em 15 de janeiro de 1918, a nova entidade científica foi a primeira de seu gênero na América Latina, surgindo apenas dez anos depois de sua congênere francesa e seis anos após a britânica, fator que aponta para a pequena

\footnotetext{
3 Nas formulações seminais do próprio Galton, considerado o "pai" da eugenia, já estava presente esse traço característico dos diferentes movimentos eugenistas que, posteriormente, surgiriam em diferentes países, qual seja, a enorme importância da propaganda. A propaganda foi a principal forma de legitimar politicamente a aplicação das ideias eugenistas, pois, através de sua permanente divulgação pública, os pressupostos do melhoramento racial se tornariam socialmente aceitáveis: "Primeiramente, deve-se ser familiarizada como questão acadêmica, até que haja sido compreendida e aceita, de fato, em sua exata importância; segundo, deve ser reconhecida como uma matéria cujo desenvolvimento prático merece uma séria consideração; terceiro, deve ser introduzida na consciência nacional como uma nova religião." (GALTON, 1988, p. 170).
} 
defasagem temporal da institucionalização da eugenia no Brasil em relação aos países da Europa - registrando a participação de 140 membros fundadores e contando "com a participação não somente de médicos, como também de diversos setores da sociedade interessados em discutir a nacionalidade a partir de questões biológicas e sociais." (DIWAN, 2013, p. 97). Sua organização foi capitaneada pelo próprio Kehl, que assumiu o cargo de secretário geral e se tornaria, como afirmei anteriormente, a principal referência do movimento eugenista local. A presidência da instituição coube ao médico Arnaldo Vieira de Carvalho (1867-1920), ninguém menos que o então diretor da prestigiada Faculdade de Medicina de São Paulo. Entre seus sócios fundadores encontravam-se homens de ciência nacionalmente consagrados, como Belisário Penna e Arthur Neiva, destacados por sua atuação na cruzada sanitarista idealizada por Oswaldo Cruz, o que demonstra a relação intelectual que imediatamente se estabeleceu entre os teóricos sanitaristas-higienistas e os teóricos eugenistas ${ }^{4}$. Além disso, tornaram-se membros os psiquiatras Antonio Austregésilo (1876-1960) e Juliano Moreira (1873-1932), bem como o futuro escolanovista Fernando de Azevedo (1894-1974).

De acordo com Pietra Diwan (2013, p. 99), o jornal O Estado de São Paulo definiu a cerimônia de fundação da entidade científica como "uma noite memorável". A imprensa local "elogiou e registrou a formação dessa área do saber, e acompanhou a discussão sobre os problemas nacionais acerca da composição racial da população brasileira." (DIWAN, 2013, p. 99). A repercussão pública do surgimento da Sociedade Eugênica de São Paulo foi extremamente favorável aos propósitos dos homens de ciência que pretendiam desenvolver os preceitos da eugenia, permitindo que a doutrina de Galton fosse saudada “como uma nova ciência capaz de introduzir uma nova ordem social por intermédio do aperfeiçoamento da raça humana." (STEPAN, 2005, p. 57). A posição de maior destaque dentro da instituição, bem como na esfera pública de sua atuação, coube a Kehl, que na qualidade de secretário-geral organizava "reuniões cuja orientação combinasse com sua própria visão de eugenia." (STEPAN, 2005, p. 57) - realizadas no Saguão da Santa Casa de Misericórdia, local tradicionalmente utilizado para eventos científicos da classe

\footnotetext{
4 Estabelece-se, nesse contexto, a relação da eugenia com a higiene e o saneamento, pois caberia aos médicos "sanitaristas a implementação de grandes planos de atuação nos espaços públicos e privados da nação, enquanto os higienistas seriam responsáveis pelas pesquisas e pela atuação cotidiana no combate às epidemias e às doenças que mais afligiam as populações." (SCHWARCZ, 1993, p. 206).
} 
médica, como os encontros da prestigiada Sociedade de Medicina e Cirurgia. Na ata da sessão inaugural, realizada no dia 15 de janeiro de 1918, é possível encontrar a definição que Kehl emprestou aos fins da nova entidade científica:

Ella estuda as leis da hereditariedade, esmiuçalha as questões de evolução e descendencia, tirando desses conhecimentos as bases applicaveis à conservação e melhoria da especie humana. Nesta sociedade serão discutidas as questões relativas à influencia do meio, do estado economico, da legislação, dos costumes, do valor das gerações successivas e sobre as aptidões physicas, intelectuais e moraes, sempre tirando dessas discussões idéas destinadas a bem de nossa raça. Sendo a eugenía uma sciencia intimamente ligada à biologia, da qual faz parte, e de outras sciencias das quais the derivam grandes ensinamentos, todas estas terão de ser consideradas na sociedade. (SOCIEDADE..., 1919, p. 6)

Esse programa expressava as ambições quase ilimitadas do nascente movimento eugenista. Para que o melhoramento racial pudesse ser realizado, não bastaria aperfeiçoar a constituição biológica da população; seria necessário também transformar radicalmente o meio em que esse corpo coletivo vivia, ou seja, a sociedade. Em outro texto seminal, também publicado nos Annaes de Eugenía, sob o título Que é Eugenía, Kehl (1919c, p. 119) ilustra essa tendência utópica (e totalitária) do discurso eugenista ao propor o seguinte jogo de palavras: "O homem perfeito é um homem feliz; a sociedade de homens felizes seria o ideal. Para que este ideal se realize cumpre ir plantando desde já as sementes que nos fornece a Eugenía”. Os ensinamentos científicos de Galton, que atuariam em favor da promoção da felicidade humana, deveriam ser reconhecidos como elementos da religião moderna "que tem por escopo prégar preceitos eugenicos dentro do seu dogma: a saude integral do corpo e do espirito" (KEHL, 1919c, p. 119). O maior objetivo dessa religião científica seria empreender a "lucta pela defesa da raça" (KEHL, 1919c, p. 222), único meio possível de realizar a "uniformidade dos homens segundo um padrão, com índice optimo de robustez." (KEHL, 1919c, p. 220).

Esse ideal da uniformização biológico-racial do "homem brasileiro" revela, convém ressaltar, o caráter normativo do discurso produzido pelo movimento eugenista. A eugenia, de acordo com Silva (2015, p. 18), vai prontamente "se instituindo como uma forma de poder-saber fundamental para as novas 'verdades' que deveriam guiar os rumos da sociedade." Sendo uma das expressões mais acabadas da lógica científica biologicista, 
pois tributária do racismo científico e do darwinismo social, ela pretende "servir de base para os planejadores sociais organizarem as condições a partir das quais a sociedade acordaria sobre seu futuro, quem deveria continuar ou ficar pelo caminho." (SILVA, 2015, p. 18). O fundamento da reforma social projetada pelos teóricos eugenistas seria a normalização biológica da população nacional, agora passível de ser realizada através da aplicação racional dos ensinamentos da ciência do melhoramento racial. Neste sentido, o éthos biopolítico desse discurso eugenista está caracterizado, acima de tudo, pela ambição de que a eugenia se tornaria "um agente de transformação da vida humana." (FOUCAULT, 1988, p. 155), intervindo em favor da realização de seu telos, o ideal da regeneração racial da população brasileira e sua consequência lógica, o progresso nacional.

Essa gestão da constituição biológico-racial do corpo coletivo da nação revelou-se mais complexa à medida que procurou abarcar, para além da tradicional preocupação com os rumos da mestiçagem racial e do branqueamento pela correta orientação da imigração, a necessidade de intervir em favor do combate às doenças que prejudicavam a vida da população brasileira. Essa inflexão discursiva está intimamente relacionada ao alinhamento estratégico dos teóricos eugenistas aos propósitos da missão sanitaristahigienista, pois, à medida que "o credo eugênico conquistava novos convertidos, a linguagem da eugenia começou a incorporar discussões científicas sobre saúde." (STEPAN, 2005, p. 58). Levando-se em consideração o conteúdo dos trabalhos publicados nos Annaes de Eugenía, é possível observar como os estudiosos organizados em torno da Sociedade Eugênica de São Paulo também passaram a definir como fatores disgênicos as doenças que tinham origem na ausência de condições higiênicas e sanitárias adequadas.

A própria problemática do combate às doenças hereditárias foi identificada com a necessidade de eliminar a herança biológica dos tipos raciais degenerados, como os negros e os mulatos, considerados pela elite educada e pelos homens de ciência como "preguiçosos, indisciplinados, doentes, ébrios e em permanente vagabundagem." (STEPAN, 2005, p. 48). Não se pode perder de vista, portanto, que os teóricos locais que compuseram o movimento intelectual em favor da eugenia - que, em sua acepção mais original, é a ciência do aprimoramento racial — faziam parte de "uma elite convencida do 
poder da ciência de criar 'ordem e progresso' (lema da República) e perturbada pela composição racial do país." (STEPAN, 2004, p. 339).

\section{A constituição da noção de educação eugênica nos Annaes de Eugenía}

Durante as três primeiras décadas do século $X X$, essa elaborada gestão da constituição biológico-racial do corpo coletivo nacional, concebida pelo emergente movimento eugenista, tornou-se mais complexa e assumiu novos contornos. Uma das dimensões da proliferação tentacular desse discurso científico produzido pelos teóricos eugenistas foi justamente sua incidência sobre o campo da Educação. A Sociedade Eugênica de São Paulo, como afirmou Vera Beltrão Marques (1994, p. 54), tinha seu interesse centrado nos "estudos da hereditariedade, pela educação moral, educação higiênica e sexual".

Tendo em conta o teor de alguns dos textos publicados nos Annaes de Eugenía, a chamada educação eugênica seria uma das formas mais efetivas de empreender estratégias biopolíticas voltadas para a profilaxia dos chamados "venenos raciais", que prejudicavam o desenvolvimento pleno das capacidades vitais da população brasileira. De forma muito peculiar, os teóricos eugenistas insistiram recorrentemente sobre a necessidade de valer-se de medidas educativas para vulgarizar os conhecimentos sobre a ciência do melhoramento racial para um público mais amplo, possibilitando que os ensinamentos da nova ciência fossem incorporados ao modo de vida da população brasileira. Daí a centralidade que a educação eugênica prontamente assumiu nas reflexões dos teóricos locais, constituindo-se em um elemento estratégico para o sucesso da campanha eugenista posteriormente empreendida no Brasil.

A promoção da educação eugênica — uma educação dedicada ao nobre propósito do melhoramento racial da população brasileira - seria determinante para a materialização do programa de intervenções proposto pelo movimento eugenista. $\mathrm{Na}$ medida em que o fundamento da eugenia seria instituir formas de condução da reprodução humana, definindo um conjunto de medidas objetivando o controle do fenômeno biológico da hereditariedade, o exercício sistemático da educação eugênica possibilitaria aos futuros pais tomarem conhecimento dos cuidados a serem observados 
para evitar que os fatores disgênicos — causadores de degenerescência racial — fossem transmitidos às novas gerações.

Como exultou Kehl em diversas oportunidades, aos "cruzados do eugenismo" caberia ensinar o verdadeiro caminho para o melhoramento humano, ou seja, esses homens de ciência teriam por missão transmitir os preceitos da ciência de Galton. Os "prosélitos do melhorismo" deveriam, sem hesitação, assumir a responsabilidade eugênica de semear seus "preceitos doutrinarios a bem da humanidade, preceitos esses que são conselhos de bem viver e de bem proceder" (KEHL, 1919b, p. 181). Por isso, desde a criação da Sociedade Eugênica de São Paulo, os teóricos do melhoramento racial insistiram no princípio galtoniano de que seria primordial realizar "a educação eugenica dos ignorantes, que são victimas de tantos males perfeitamente evitáveis." (KEHL, 1919b, p. 181). Os teóricos eugenistas, segundo Marques:

[...] vislumbraram nos poderes educacionais da escola não somente um instrumento fundamental de persuasão para a realização dos casamentos eugênicos, como também descobriram o espaço da escola como importante fórum de gerência populacional - o lócus por excelência da educação sexual. (MARQUES, 1994, p. 104)

Os Annaes de Eugenía documentam justamente a forma como, muito precocemente, a tarefa de difundir os preceitos da eugenia por meio da educação foi considerada uma prioridade para os propositores da chamada campanha eugênica. Como afirmou Kehl em Darwinismo social e Eugenía, o sucesso da eugenia dependeria de medidas educativas efetivas:

Não precisa de elogios laudatorios uma doutrina scientifica cujo programa é esforçar-se para conseguir a almejada felicidade humana. Esta felicidade se consubstancia na robustez physica, no vigor intelectual, na dignidade moral. Pois bem, é a Eugenía, com os seus preceitos, a eliminadora das causas da degeneração, que torturam a vida dos nossos semelhantes. A sciencia de Galton, para atingir a sua meta, precisa, sim, de proselytos apaixonados que the emprestem suas luzes para tornar 0 "ideal eugenico" uma parte do systema de educação. Será com o auxilio de apaixonados por esta doutrina, que, pregando no lar, na escola, em toda parte, os "sentimentos de responsabilidade racial", poderá atingir o aperfeiçoamento physico e moral da especie humana. A Eugenía muito precisa e muito espera dos médicos. São estes que, alliados aos educadores e legisladores, constituem a plêiade principal da eugenisação. (KEHL, 1919b, p. 182-183) 
Para que o ideal eugênico pudesse se tornar uma realidade, portanto, seria imprescindível desenvolver junto à população brasileira a devida consciência acerca de sua responsabilidade racial para com o futuro nacional. Uma tal consciência, que permitiria normalizar corpos e espíritos em acordo com o ideal eugênico, só poderia surgir de uma ampla ação educativa voltada para o ensino dos preceitos eugenistas "em toda a parte". Iniciada nos lares, pois aos pais "cabe a maior responsabilidade na organização moral e intelectual dos filhos", essa educação deveria ser continuada nas escolas, que realizam a "educação pedagógica, por meio da qual o homem in posse se transmuda em homem in actu." (KEHL, 1923, p. 350). Dada a centralidade que a educação prontamente assumiu junto ao projeto eugenista, tanto os pais quanto os professores foram imediatamente convocados para o dever de atuar, através da educação eugênica, em favor da regeneração racial da população brasileira.

No entanto, como se depreende da supracitada exultação de Kehl, a educação eugênica foi então definida enquanto um trabalho pedagógico que deveria ter larga amplitude social e que, portanto, não poderia ficar restrito aos processos educativos desenvolvidos no âmbito da escola. É preciso lembrar que, apesar do investimento que desde o início do período republicano havia sido feito para instituir a educação escolar primária, fazia-se evidente que a escola ainda se constituía como instituição social relativamente incipiente durante as primeiras décadas do século XX. Como demonstrou Marta Chagas de Carvalho (1989, p. 7), a maior dívida republicana com a educação residiu no problema de que a escola tenha sido "facultada a poucos", alijando a maior parte da população nacional, composta em grande parte por mestiços e negros descendentes dos libertos em 1888, do acesso ao ensino escolar.

Durante toda a Primeira República (1889-1930), a escolarização foi privilégio de parcelas relativamente reduzidas da população nacional, atingindo as classes populares principalmente nos centros urbanos. Em uma sociedade estruturada sobre relações sociais legadas do período em que vigorou a escravidão, a concepção de cidadania então em vigor excluía largas parcelas da população do exercício dos direitos e deveres previstos na Constituição de 1891. Consequência da patente insuficiência da educação escolar, que reservava seus benefícios a grupos sociais bastante restritos, é a estimativa de que em 1920 cerca de "75\% dos brasileiros eram analfabetos." (VEIGA, 2007, p. 253). 
Tendo esse dado em conta, é possível compreender por que os teóricos eugenistas postulavam que as medidas educativas que deveriam contribuir para o aprimoramento biológico do povo brasileiro não deveriam passar apenas pela escola.

No entanto, para além da incipiente escolarização, a definição desse amplo raio de ação da educação eugenista na sociedade - na escola e fora dela — pode ser melhor compreendida se atentarmos para as opções teóricas que fundamentaram o discurso produzido pelo movimento eugenista que se organizou em torno da Sociedade Eugênica de São Paulo. Os dissensos teóricos dentro do campo da eugenia, neste sentido, não podem ser de modo algum ignorados. A concepção que um eugenista possuía do melhoramento racial dependia, acima de tudo, de "seu entendimento da natureza da hereditariedade" (STEPAN, 2004, p. 346). Apesar do avanço da genética mendeliana durante as primeiras décadas do século $\mathrm{XX}$, os eugenistas lamarckianos continuaram aceitando o postulado da hereditariedade dos caracteres adquiridos e da ação das influências do meio sobre o plasma germinativo. Essa compreensão lamarckiana da hereditariedade foi predominante junto ao movimento eugenista local até, ao menos, a passagem para a década de 1930.

O discurso eugenista formulado nas páginas dos Annaes de Eugenía procurou demonstrar que fatores disgênicos adquiridos durante a vida dos indivíduos como o alcoolismo, a sífilis ou a tuberculose, deveriam ser permanentemente combatidos, pois uma vez adquiridos pelo organismo humano, muito provavelmente seriam herdados por seus descendentes ${ }^{5}$. Já que os caracteres adquiridos eram transmitidos hereditariamente, esses venenos raciais se constituiriam em agentes causadores da degenerescência, produzindo prejuízos biológicos que seriam incorporados pelas próximas gerações, prejudicando o futuro do corpo coletivo da nação - a população brasileira. O mesmo princípio lamarckiano de que as "mudanças induzidas de fora em um organismo vivo poderiam ser transmitidas às futuras gerações.” (STEPAN, 2005, p. 78), em compensação, permitia crer que os "melhoramentos adquiridos durante a vida de um indivíduo

\footnotetext{
${ }^{5}$ Nesse sentido, a compreensão do alcoolismo como um dos mais perigosos venenos raciais se revela exemplar, como argumenta Stepan (2004, p. 350): "O estilo neolamarckiano reformista da eugenia foi representado em sua forma mais pura, talvez, nas campanhas antialcoólicas da década de 1920. De há muito encarado como problema social e moral característico da população negra e pobre, particularmente, o alcoolismo foi reformulado como inimigo da raça porque o vício provocaria condições hereditárias ligadas ao crime, à delinquência juvenil, à prostituição e às doenças mentais entre os pobres das zonas rurais e urbanas."
} 
poderiam ser transmitidos geneticamente." (STEPAN, 2005, p. 83). A concepção lamarckiana da eugenia, portanto, também autorizava a projeção otimista de que a racionalidade científica poderia orientar intervenções sobre a constituição racial da população brasileira, através de amplas reformas sociais fundamentadas nos preceitos eugênicos.

A chamada eugenia positiva, em face da eugenia negativa, demonstrou atender melhor aos anseios dos homens de ciência que formularam o projeto eugenista no Brasil das primeiras décadas do século $X^{6}$. Fundamentada sobre a concepção lamarckiana da hereditariedade, as medidas próprias da eugenia positiva se ancoravam no pressuposto galtoniano de que a evolução biológica não era o resultado "de forças materiais cegas, mas de mudanças provocadas por vontade e escolha." (STEPAN, 2005, p. 83). Essa conjugação de fatores criou as condições para que a educação eugênica se tornasse, ao lado das reformas sanitaristas e higienistas anteriormente mencionadas, uma estratégia preferencial de intervenção em favor do melhoramento racial da população brasileira. Do mesmo modo que as medidas sanitárias e higiênicas poderiam realizar a prevenção da aquisição dos caracteres hereditários indesejáveis, e, por consequência, de sua provável transmissão, a educação eugênica deveria se constituir em uma forma igualmente efetiva de empreender a profilaxia dos venenos raciais e impedir o avanço da degenerescência biológica. Uma vez que a educação eugênica fosse amplamente difundida na sociedade, o meio, a população brasileira poderia ser alertada quanto aos prejuízos da inferioridade racial e ser esclarecida quanto aos enormes benefícios da eugenia.

A educação eugênica, agindo a partir de fora do organismo vivente, produziria efeitos favoráveis ao melhoramento racial, contribuindo para a normalização biológica projetada pelo discurso eugenista. Uma educação atenta aos preceitos biopolíticos da eugenia incutiria os devidos "sentimentos de responsabilidade racial" na consciência da

\footnotetext{
${ }^{6}$ Enquanto a eugenia positiva, que se desenvolveu na trilha das proposições mais centrais de Galton, procurou promover a reprodução dos indivíduos portadores das melhores qualidades biológico-raciais, na medida em que tinha por objetivo principal a criação do "haras humano", ou seja, atuando no sentido de povoar "o planeta com gente sã, estimulando casamentos entre os bem dotados biologicamente e desenvolvendo programas educacionais para a reprodução consciente de casais saudáveis" (DIWAN, 2013, p. 50). Já a eugenia negativa, por sua vez, propunha a aplicação de medidas mais drásticas como a esterilização e a eliminação física de indivíduos e grupos sociais considerados racialmente inferiores, evitando assim a reprodução dos hereditariamente inadequados, prevenindo "os nascimentos dos 'indesejáveis' biológica, psicológica e socialmente através de métodos mais ou menos compulsórios." (DIWAN, 2013, p. 50).
} 
população nacional. Por isso Kehl (1919c, p. 222) afirmava recorrentemente — como o fez em seu seminal Que é a eugenia, publicado nos Annaes - que "Instruir é eugenisar." Desse modo, uma educação realizada de acordo com os dogmas da ciência do melhoramento racial teria como função primordial promover a eugenização do corpo coletivo da nação, tornando-o apto para tomar parte do progresso nacional.

Outro teórico que se notabilizou, ao lado de Renato Kehl, na defesa da promoção da chamada educação eugênica foi o escolanovista Fernando de Azevedo, autor de dois textos publicados nos Annaes de Eugenia. Bacharel formado em 1918 pela prestigiada Faculdade de Direito de São Paulo, Azevedo foi membro fundador e Primeiro Secretário da Sociedade Eugênica de São Paulo. A militância desse patrono da educação nacional em favor da eugenia é, em geral, pouco considerada em sua trajetória biográfica — da qual se atribui relevo ao fato de ter redigido o célebre Manifesto dos Pioneiros da Educação Nova de 1932.

Entre seus trabalhos de juventude, no entanto, está a conferência intitulada $O$ segredo da marathona, apresentada diante da plateia que frequentava as palestras da entidade eugênica paulistana. A referida conferência, como é possível perceber através da leitura do texto posteriormente publicado nos Annaes, parece ter delineado as bases de seu ativismo em prol da promoção do que chamava de cultura esportiva. Azevedo procurou reelaborar a definição corrente de eugenia, conferindo grande relevância à educação física no interior do projeto eugenista. Para tanto, argumentava que, além de preocupar-se com a supressão dos venenos raciais transmitidos hereditariamente, compondo uma população doente marcada pela degenerescência, dever-se-ia dar atenção para a vocação "melhorista" da ciência da eugenia: "Não basta, pois, curar os doentes, é preciso melhorar os sãos." (AZEVEDO, 1919b, p. 117) e, para tanto, seria necessária "a aplicação de uma educação enérgica para a conquista da plenitude de suas forças physicas e Moraes." (AZEVEDO, 1919b, p. 117).

Do seu ponto de vista, portanto, a ciência do melhoramento racial teria de ser concebida como uma forma de promover a regeneração do corpo coletivo nacional por meio de uma "completa cultura esportiva, que os impulsione, a todo panno, dos lagos mortos onde jazem estacionarios pela inercia, para o vasto e esplendido tumultuar da vida hygienica intensamente vivida no ar acrysolado no ouro do sol." (AZEVEDO, 1919b, p. 
117). Habitar um ambiente adequado, leia-se saneado e higienizado, seria fundamental para que a população brasileira fosse adequadamente eugenizada. Contudo, para que o organismo humano pudesse tirar o maior proveito possível dessa ação positiva do meio sobre si e, por sua vez, pudesse desenvolver ao máximo suas capacidades vitais, seria necessário o desenvolvimento de uma cultura esportiva, que somente a educação física poderia ensinar:

A campanha do saneamento localizada nestas zonas polluidas de endemias, não é, eugenicamente falando, uma tarefa única, mas sim a primeira face de um cyclopeo trabalho de regeneração, de que o segundo aspecto, não menos importante, é o revigoramento, por meio da educação physica continua e methodizada, desta raça que o saneamento liberou de causas anemiantes e reintegrou no estado hygido, mas que ainda continuaria a soffrer do mal inquietante da depressão physica. (AZEVEDO, 1919b, p. 117)

Os benefícios da cultura esportiva, elemento fundamental para o desenvolvimento de uma verdadeira educação eugênica, não ficariam restritos aos praticantes da educação física. Afinal, conforme os preceitos eugênicos, as melhorias biológicas advindas da prática de esportes seriam transmitidas hereditariamente para as próximas gerações. Como afirmou Azevedo (1919a, p. 150) em Meninas feias e meninas bonitas, outro trabalho de sua autoria encontrado nos Annaes de Eugenía, o descuido da família e da escola para com "a rotina da educação physica de nossas filhas" estaria fazendo delas "um instrumento inconsciente para encher o mundo de criaturas doentias e abastardar a raça pela acumulação hereditária, por largas gerações, da degenerescência physica". A educação física, portadora de inegável função eugênica regeneradora, possibilitaria a reversão desse processo nefasto de degenerescência racial ao qual as jovens estavam sujeitas. Nesse sentido, Azevedo era enfático ao postular que:

A regeneração physica da mulher brasileira é certamente o meio mais logico, mais seguro e mais direto de obter-se de futuro uma geração sadia e robusta, em substituição a esta de hoje, que, em geral, se ankysola em attitudes scolioticas e enfezadas, estiolando-se nos rebentos de uma próle franzina, que surge muitas vezes sobre as ruinas da saúde das mães, quando não seja sobre o sacrifício de sua propria vida... Que podemos de facto esperar de meninas fracas, para quem a maternidade seja uma catástrofe, sinão uma floração cada vez mais rachitica e doentia? (AZEVEDO, 1919a, p. 150-151) 
A prática da educação física entre as futuras mães, eliminando os caracteres biológicos causadores da degenerescência, faria brotar "em seiva exuberante de saude e na esbeltez graciosa dos contornos uma explendida mocidade feminina." (AZEVEDO, 1919a, p. 151). De acordo com o eminente escolanovista, os teóricos eugenistas deveriam sugerir a adoção de um modelo escolar norte-americano, baseado na prática sistemática da educação física para as moças. Nessas escolas, onde já haviam sido formadas milhares de jovens, as internas "usufruem os múltiplos beneficios de um ambiente hygienico do campo, partilhando o tempo entre exercícios de bola, remo e natação e estudos práticos sobre a formação e direção do lar." (AZEVEDO, 1919a, p. 151).

Para Azevedo, os resultados eugênicos do trabalho pedagógico realizado nesse tipo de instituição escolar a tornavam, de fato, digna de ser tomada como exemplo no Brasil. A educação eugênica ali desenvolvida, afinal, vinha produzindo corpos femininos "sadios e bem talhados, nervos postos a prova para a realização do propósito do amor e do papel bio-educativo que lhes está destinado" (AZEVEDO, 1919a, p. 151). Esse tipo de ensino, atento aos propósitos do melhoramento racial, estaria colocando essas jovens à "altura de seus deveres e responsabilidades e da eficaz contribuição, com que devem concorrer para o aperfeiçoamento psyco-physico da raça.” (AZEVEDO, 1919a, p. 151).

A educação física, fundamentada em uma orientação eugenista, teria por objetivo desenvolver a responsabilidade reprodutiva das mulheres, constituindo-se como uma base para a formação da responsabilidade racial idealizada pela educação eugênica?. Azevedo entendia, por outro lado, que a iniciativa de generalizar a educação física nas escolas também seria fundamental para que se completasse o processo de homogeneização racial da população brasileira, vislumbrado pelos teóricos racialistas das últimas décadas do século XIX e projetado pelos teóricos eugenistas das primeiras décadas do século XX. A “elaboração regenerativa e modeladora da educação physica”, atuando em favor da ação eugênica em curso como decorrência da imigração europeia,

\footnotetext{
7 Conforme Goelnner (2009, p. 81): "Tanto quanto realizar um bom casamento, evitando, por exemplo, as relações inter-raciais, fortalecer o corpo feminino passa a ser uma necessidade nacional (Kehl, 1926). Não é sem razão, portanto, que vários intelectuais de destaque reconheceram a prática de atividades físicas como necessária às mulheres, ainda que sejam várias as restrições impostas e diversos os cuidados a serem seguidos (AZEVEDO, 1920; LOYOLA, 1932). Suas recomendações e prescrições, no que tange aos exercícios corporais femininos, direcionam-se para a preservação e constituição de uma boa maternidade, considerada, então, a mais nobre missão da mulher, pois dela depende a regeneração da própria sociedade."
} 
contribuiria decisivamente para que a população brasileira fosse "integrando numa nacionalidade homogênea e característica, vigorosa e apurada estas fluctuantes correntes ethnicas, caldeadas pelo dynamismo mesológico e pelo cruzamento." (AZEVEDO, 1919b, p. 132).

A reflexão de Azevedo acerca da educação física é, portanto, profundamente marcada pela concepção de que a cultura esportiva deveria engendrar a regeneração racial da população brasileira conforme os preceitos da eugenia. Como afirmou Silvana Vilodre Goelnner, nessa perspectiva característica da década de 1920, à educação física:

[...] é conferida a tarefa de corrigir as deficiências da raça brasileira, ao mesmo tempo em que se deve modelar o corpo feminino desenhando sobre ele novos contornos, nas quais a harmonia corporal, a graça, a doçura e a delicadeza devem ser preservadas. A construção de um organismo forte estava assentada no trinômio "saúde, força e beleza", pois desse trinômio resultaria a força de uma geração de novas criaturas, e, por conseguinte, de um novo país. (GOELNNER, 2009, p. 83)

Não se pode perder de vista que o ideal eugênico do melhoramento racial, que tomou sua forma seminal no Brasil nas teorizações científicas encontradas nos Annaes de Eugenía, esteve presente de forma explícita ou implícita nas reformas educacionais realizadas nas décadas de 1920 e 1930. Os intelectuais responsáveis pelas reformas educacionais do período, organizados em torno da Associação Brasileira de Educação, criada em 1924, demarcaram a emergência de uma visão propriamente moderna da educação. Como afirmou Cynthia Greive Veiga (2007, p. 254), apesar das eventuais discordâncias entre os reformadores, seu principal objetivo foi "reinventar a educação para adaptar os indivíduos à sociedade de seu tempo." Sendo amplamente difundida a ideia da inferioridade racial da população brasileira, a prerrogativa fundamental de “fundamentar a nova educação em parâmetros científicos." (VEIGA, 2007, p. 254) os conduziu diretamente para a proposição de métodos pedagógicos fundados na biologia, leia-se sobretudo eugenia e higiene.

Conforme Jerry D’avila (2006, p. 13), isso resultou numa concepção de modernização educacional constituída pari passu aos pressupostos do discurso eugenista, na qual "a maior parte dos brasileiros, pobres e/ou pessoas de cor, eram subcidadãos 
presos à degeneração - condição que herdavam de seus antepassados e transmitiam a seus filhos, enfraquecendo a nação.” Os modernizadores, como era próprio dos mais arraigados adeptos da cruzada eugenista, possuíam uma enorme "fé em sua capacidade de mobilizar ciência e política para redimir essa população, transformando-as em cidadãos-modelo." (D’AVILA, 2006, p. 13). Desse modo, não surpreende que, anos mais tarde, no Manifesto dos Pioneiros da Educação Nova, Azevedo tenha insistido que o educador moderno deveria ser um intelectual "de larga visão que, dotado de espírito científico, lançaria mão de todas as técnicas disponíveis desenvolvidas para impulsionar a administração dos serviços escolares." (SAVIANI, 2011, p. 243) ${ }^{8}$.

Sendo devidamente difundidos na sociedade através da educação eugênica recomendada por teóricos como Kehl e Azevedo, os preceitos eugênicos poderiam intervir sobre os processos vitais, induzindo modificações biológicas que seriam transmitidas hereditariamente, influindo diretamente no processo de normalização racial da população brasileira. Na própria gênese do discurso eugenista, como procurei discutir no transcorrer deste artigo, a educação surgiu como uma forma privilegiada de empreender a eugenização do corpo coletivo da nação. A educação eugênica, teorizada nas páginas dos Annaes de Eugenía, prontamente se constituiu como uma das formas pelas quais se pretendia suprimir a degenerescência em favor do melhoramento racial da população nacional. A escrita da história das relações entre eugenia e educação no Brasil não deve ignorar esse vínculo seminal, que define uma tendência recorrente no projeto biopolítico proposto pelo movimento eugenista durante as décadas de 1920 e 1930, na qual a educação se subordinaria à eugenia ao mesmo tempo em que esta última se constituiria como fundamento da própria educação.

\footnotetext{
${ }^{8}$ O Manifesto dos Pioneiros da Educação Nova, que teve como principal redator o próprio Azevedo, não poderia deixar de reconhecer a "finalidade biológica da educação", bem como que "o direito do indivíduo à educação se funda na biologia" (SAVIANI, 2011, p. 245). É inconteste, neste sentido, que o determinismo biológico característico do discurso eugenista animou a reforma educacional proposta por Azevedo em 1932.
} 


\section{Referências}

AZEVEDO, Fernando de. Meninas feias e meninas bonitas. In: SOCIEDADE EUGÊNICA DE SÃO PAULO. Annaes de eugenía. São Paulo: Ed. Revista do Brasil, 1919a. p. 148-153.

AZEVEDO, Fernando de. O segredo da marathona. In: SOCIEDADE EUGÊNICA DE SÃO PAULO. Annaes de eugenía. São Paulo: Ed. Revista do Brasil, 1919b. p. 113-136.

CARVALHO, Marta Chagas de. A escola e a República. São Paulo: Brasiliense, 1989.

D’AVILA, Jerry. Diploma de brancura: política social e racial no Brasil (1917-1945). São Paulo: Editora Unesp, 2006.

DIWAN, Pietra. Raça pura: uma história da eugenia no Brasil e no mundo. São Paulo: Contexto, 2013.

FOUCAULT, Michel. História da sexualidade I: a vontade de saber. Rio de Janeiro: Edições Graal, 1988.

GALTON, Francis. Herencia y eugenesia. Madrid: Alianza Universidad, 1988.

GOELNNER, Silvana Vilodre. A produção de corpos hígidos: atividade física, saúde e nacionalismo no Brasil no início do século XX. In: GRANDO, Beleni Saléte (org). Corpo, educação e cultura: práticas sociais e maneiras de ser. Ijuí: Editora Unijuí, 2009. p. 75-94.

KEHL, Renato Ferraz. Conferencia de propaganda Eugenica. In: SOCIEDADE EUGÊNICA DE SÃO PAULO. Annaes de eugenía. São Paulo: Ed. Revista do Brasil, 1919a. p. 65-80.

KEHL, Renato Ferraz. Darwinismo Social e Eugenía. In: SOCIEDADE EUGÊNICA DE SÃO PAULO. Annaes de eugenía. São Paulo: Ed. Revista do Brasil, 1919b. p. 175-184.

KEHL, Renato Ferraz. Melhoremos e prolonguemos a vida: a valorização eugenica do homem. Rio de Janeiro: Livraria Francisco Alves, 1923.

KEHL, Renato Ferraz. Que é Eugenía. In: SOCIEDADE EUGÊNICA DE SÃO PAULO. Annaes de eugenía. São Paulo: Ed. Revista do Brasil, 1919c. p. 217-224.

MARQUES, Vera Regina Beltrão. A medicalização da raça: médicos, educadores e discurso eugênicio. Campinas: Editora da UNICAMP, 1994.

SAVIANI, Dermeval. História das ideias pedagógicas no Brasil. Campinas: Autores Associados, 2011.

SCHWARCZ, Lilia Moritz. O espetáculo das raças: cientistas, instituições e questão racial no Brasil (1870-1930). São Paulo: Companhia das Letras, 1993. 
SOCIEDADE EUGÊNICA DE SÃO PAULO. Annaes de eugenía. São Paulo: Ed. Revista do Brasil, 1919.

STEPAN, Nancy Leys. A hora da eugenia: raça, gênero e nação na América Latina. Rio de Janeiro: Editora Fiocruz, 2005.

STEPAN, Nancy Leys. Eugenia no Brasil (1917-1940). In: HOCHMAN, Gilberto (org.). Cuidar, controlar, curar: ensaios históricos sobre saúde e doença na América Latina e Caribe. Rio de Janeiro: Fiocruz, 2004. p. 331-382.

VEIGA, Cynthia Greive Veiga. História da Educação. São Paulo: Ática, 2007.

Recebido em: 03/06/2018 Revisões requeridas: 30/07/2018 Aprovado em: 27/09/2018

Universidade do Estado de Santa Catarina - UDESC Programa de Pós-Graduação em Educação - PPGE Revista Linhas Volume 21 - Número 45 - Ano 2020 revistalinhas@gmail.com 